\title{
Relatividade dos crimes no tempo e no espaço
}

\author{
Cadeira: Filosofia do Direito \\ Professor: Doutor João Arruda \\ Aluno: Pedro Antonio de Oliveira Ribeiro Neto
}

Quem quer que estude a evolução do direito, ha de encontrar, chegando ao capítulo penal, dificuldade intransponivel se quiser estabelecer a noção exata do que a humanidade considéra crime.

Com muita razão verificou GEorge GodwIN, na sua obra "Cain or the future of crime", que a natureza dos delitos muda com os diversos conceitos de moral e com as diferentes necessidade sociais, variando no tempo e no espaço. E cita exemplo frisante de que os atos humanos pódem ser considerados criminósos conforme as condições da sociedade em cada momento, narrando um fato observado na Inglaterra, durante a Guerra mundial: - Os homens que, em 1916, por idéias religiosas ou de humanidade, recuando ante a idéia da morte, se recusavam a prestar serviço militar, foram considerados criminósos pelo Estado. E' que nas épocas de guerra, aqueles que matam deixam de ser assassinos para serem heróis. Então o assassínio se torna virtude.

Tudo é relativo no passado, no presente ou no futuro, e, ao mesmo tempo, as ilegalidades do Oriente pódem ser consideradas direito no Ocidente. 
Mas o que hoje aponta com tanto brilho o cronista da Inglaterra, já fôra notado ha mais de século pela sabedoría de Pereira e Souza, nas "Classes dos Crimes", onde no $\S 15$ declaar que "os crimes, assim públicos como particulares, estão sujeitos a modificações gerais e particulares", e no $\S 16$ explica: "As modificações gerais provém: primeiro da forma do govêrno, segundo do clima, terceiro dos costumes, quarto da opinião pública, quinto do caráter nacional"

$\mathrm{E}$ é de ver que muita razão assiste ao grande comentador das Ordenações, na classificação feita dos modificadores criminais.

Nâo se poderá negar, por exemplo, que a mudança de Govêrnos traga consigo a punição de nóvos crimes. Dos crimes políticos, que têm intima relação com os governantes, trataremos depois. Mas provando a relação das penas com o govêrno, mostrando a influência dos governadores sôbre as leis, avulta o contraste entre o Digesto e o Código, - aquele, óbra de sábios jurisconsultos; - êste, produção de uma administração despótica. (PASToret - Des lois pénales).

No século XIX, na Inglaterra, com a mudança de govêrnos, nada menos de cento e vinte e oito nóvos crimes punidos com a pena de morte foram adicionados ao Statute Book, incluidas entre elas faltas lévíssimas como o furto de coelhos. (Comentaries, de Blackstone; Murder and the Death Penalty, de E. Roy Calvert; Chamber's Encyclo., vol. II, pag. 743).

Não se poderá negar tão pouco o que já dizia Brissot na "Théorie des lois criminelles", que o clima influindo na organização física, há-de influir tambem na organização moral dos homens. " On ne voit presque rien de juste ou d'injuste qui ne change de qualité en changeant de climat. Trois degrés d'élévation du pôle renversent toute la jurisprudence. Un méridien décide de la verité. Les lois fondamentales changent. Le droit a ses époques. Plaisante justice qu'une riviêre ou une montagne borne! Verité en-deçá des Pyrénées, erreur au-dèlá"! (Pascal, Pensées LX). 
Assim, não são de estranhar os crimes de ímpeto e os delitos sexuais, entre os povos ardentes dos trópicos, nem que haja nos países nórdicos, mais tolerância para a embriaguez. ' $\mathrm{E}$ ' natural, reflete MontesQuiEu, (Esprit des loix, livro 14, cap. 10), que onde o vinho é contrário ao clima, e por conseqüência á saúde, seja o excesso dela mais severamente catigado que nos países em que a embriaguez é pouco prejudicial á pessoa e ao Estado, e em que êle não faz os homens furiosos, mas somente estúpidos" Lei decorrente do clima é a de Mafôma, que proíbe o beber vinho aos póvos da Arábia.

Os costumes, a opinião pública e o caráter nacional, têm tambem grande influencia sôbre as leis que estabelecem as classes de crimes. Entre os povos conquistadores, familiarizados diariamente com o sangue e com a rapina, não pódem ser considerados delituósos os fatos de tal fórma considerados pelos póvos de civilização mais adiantada e de vida indolente, acostumados ao luxo e a outros vícios, bem como possuidores de outras virtudes. A própria lei de cada país, que, pelo menos em teoria, deve estar de acôrdo com os costumes do povo, não qualificará de criminósos os atos geralmente praticados e em uso entre os que vai reger, pois não produz os devidos efeitos a pena que contraria a opinião pública. Segundo Katharne Mayo, em "Mother India", os indianos, apesar da interdição imperial, destróem as crianças do sexo feminino, em obediencia secreta aos velhos usos. Conta Sir J. Frazer, no seu livro "The Golden Bough" que nas ilhas Fijian, no último século, mais de metade da população infantil era destruida, com a aprovação da comunidade.

Mas até entre os póvos de civilização refinada, como na Grecia, já se pregaram e empregaram os infanticídios, com o fim, desta vez, da perfeição da raça. Aristotéles, na Politica, ensinou que as leis deveriam proibir a alimentação das crianças mutiladas, e que os abortos poderiam ser praticados quando alguma calamidade pudesse recair sôbre a cabeça do que iria nascer. Platão defendeu a mesma idéia; e os 
espartanos atiravam inclementemente a uma caverna no pé do monte Taygetus, as crianças recem-nascidas, julgadas fracas ou defeituósas, pelos mais velhos da cidade.

Nas legislações modernas, entretanto, são geralmente consideradas criminósas, e como tais punidas, as mães que tiram a vida aos filhos pequeninos, ou que procuram matar no útero o nascituro, ainda mesmo que para esconder a própria deshonra e a própria vergonha.

E' que a idéia do crime esta presa sempre á opinião pública e aos costumes. Assim entendendo é que o velho e modernissimo Pereira e Souza já dizia:

"Huma nação guerreira não tem o mesmo espirito, nem conseqüentemente deve ter as mesmas Leis e as mesmas penas que huma nação commerciante; huma nação agricultora, que huma que se enriquece pelas suas manufacturas; huma nação inculta, que huma nação polida. Os crimes Religiosos serão mais severamente punidos em uma Theocracía, como o forão entre os Hebreos. Em hum povo militar serão maiores crimes a insubordinação, a deserção, a fraqueza que em hum povo agricultor, ou negociante. Em Esparta, cujos habitantes eram animados de hum espirito guerreiro, aquelle que fugisse em hum combate perdia os direitos de Cidadão. Os delictos contra a bôa fé do Commercio serão mais punidos nos Estados Commerciantes, como em Inglaterra ou em Genova"

Para demonstrar que a opinião pública, ás vezes orientada pelo legislador, vê o caráter criminoso em atos que antes julgava comuns, cita PAstoret um fato bastante pitoresco. "As Locrianas abandonavam-se a um luxo imoderado. ZALEuco, para o coibir não recorreu a alguma lei sumptuária que o proibisse diretamente, mas legislou deste módo:

"Nenhuma mulher livre, exceto achando-se embriagada, poderá saír da Cidade de noite, senão para o fim de prostituir-se. Só as meretrizes terão a faculdade de se adornarem de joias de prata e ouro, e de trajarem vestidos de diversas côres. Nenhum homem fará uso para o seu vestuario 
do pano de Mileto, senão o que abandonar á impudicícia" Deste módo, o sábio legislador orientou de tal fórma a opinião pública, que lógo diminuiu o luxo desmedido das Locrianas, tementes de incorrer na qualificação severa da lei, que fazia a pena redundar na própria ação exclusivamente.

Vejamos, contudo, rapidamente, porquê o assunto demandaria dezenas de volumes, alguns dos fatos qualificados de criminósos pelas Ordenações, comparando-os a vol d'oiseau com o caráter que tiveram anteriormente e com o caráter que têm nos nossos dias.

Vejamos primeiro, por ser demonstração claríssima da relatividade dos crimes no tempo e no espaço, o delito de Alta Traição ou Lésa Majestade, do qual dizia MontesQuieu que "é o maior crime que um cidadão pode cometer contra o Estado, e é de maior importancia o defini-lo bem, porquê a escuridade dele bastaría para fazer degenerar um govêrno legal em um poder arbitrário" Esse crime que era punido pelas Ordenações com "Morte natural atroz. Confiscação dos bens, ainda tendo filhos. Infamia perpétua" (Ord. liv. 1 , tit. $6, \S \S 1,2,4,5,9,10,11,13,15$. Alvará de 17 de Janeiro de 1759), servira muito antes de pretexto para que os Tiberios, os Calígulas e os Neros cometessem as mais incríveis barbaridades, como narram Tacito e Suetonio.

(Mas era natural que êsses imperadores cometessem atrocidades. Não nos surpreendem êsses fatos, desde que o julgamento dos crimes de Alta Traição fica muito a critério daqueles contra o qual são perpetrados, ou que, caprichosamente, por êles se sentem ofendidos. Pois Henrique VIII, o Nero inglês, não fez declarar Ana Bolena ré de Lesa Majestade, apenas porquê disséra que .o rei não tinha possuido inteiramente o seu coração?)

Basta, entretanto, para se ter a idéia da precaridade do conceito do crime de Alta Traição, lançar uma vista de olhos á sua história, que Pereira e Souza tão bem resume, e ás variações de pena impostas pelos próprios interessados: Os Persas, os Macedonios, os Cantagineses, os Espartanos e os 
Atenienses, puniam com a morte os réus dêste crime e os seus parentes. Castigavam-nos, os romanos da Republica livre, com açoites até a morte; - e só depois de Cornelio Sylla e Julio Cesar, foi abolido tal suplício e substituido pela pena de privação da agua e do fogo. Os imperadores seguintes, segundo os seus gênios ora brandos, ora crueîs, variaram as penalidades, até que surgiu a Constituição de Arcadio e Honorio, que mandava que os réus do crime de Lésa Majestade e os seus cumplices fossem punidos com "o ultimo suplício: - que se lhes confiscassem todos os bens; que fosse danada a sua memória; que os seus descendentes ficassem perpétuamente infames; que os filhos ficassem excluidos da herança materna, e que ao Avô só pudessem suceder por testamento; e que as filhas só pudessem ter legitima por parte da mãe"

Adotaram e aumentaram estas penas as leis de uma grande parte da Europa. Os alemães antigos enforcavam em arvores os traidores á Majestade, e os Merovíngios os puniam com os maiores suplícios. Carlos $\mathrm{V}$ decretou que os réus de tal crime fossem esquartejados, e as mulheres afogadas em água, exasperando-se as penas segundo a gravidade das circunstâncias, e confiscados os seus bens.

Na Inglaterra a pena para a alta traição era solene e horrivel. Os criminosos eram arrastados até o lugar do suplício, onde eram pendurados pelo pescoço; e se lhes arrancavam, antes que morressem, as entranhas que eram lançadas ao fogo. Cortavam-se-lhes a cabeça; e os seus corpos eram depois esquartejados. Em França eram-lhes amputadas as mãos; atenazavam-lhes o peito, lançavam-lhes por cima chumbo, resina, cera e enxofre, derretidos em azeite fervente. "Depois os seus corpos eram esquartejados, sendo puxados por quatro cavalos; queimavam-se-lhes os membros, e as cinzas a que ficavam reduzidos eram espalhadas ao vento. Os seus bens eram confiscados, as suas casas arrazadas, os seus pais e os seus filhos e descendentes banidos do reino". Pelas leis de Castela, - o traidor era puni- 
do com a morte e com a confiscação dos bens, perdendo a fidalguia e arrazando-se-lhe as casas para perpétua infamia.

Mixto das penas da Inglaterra, da França e de Castela, foram as aplicadas ao gesto de Tiradentes, - julgado nefando pela Metrópole, consagrado heroismo pelo Brasil-colônia e pela posteridade, - o que vem mais uma vez demonstrar a relatividade do conceito do crime.

Hoje não são tão severos os castigos aplicados a êsses criminosos. Mas continúa a completa arbitrariedade no julgamento e nas penas. Para provar como é relativo o crime politico, é bastante verificar que se os conspiradores vencerem e mudarem de rumo a política do país, serão êles considerados pais da Patria, (como se vê freqüentemente) em lugar de criminósos; - e a pena que lhes deveria ser aplicada, recairá severa e inclemente nos antigos governadores, que deles seriam juizes se a sorte os não ajudasse.

Os crimes de fabrico de moeda falsa, eram considerados pelas Ordenações "contra os direitos do Imperante", e reputados na França como de "Lésa Majestade de segunda cabeça" (Doma - Supplement au droit public). No Código Criminal da Toscana e no Código Imperial da Rússia, entretanto, êsses crimes eram punidos apenas como furtos qualificados, sendo considerados hoje, pelas modernas legislações, "crimes contra a fé publica"

As Ordenações, (livro 1, tit. 58, e livro 5, tit. 45), bem como o alvará de 12 de Agosto de 1717, puniam os crimes de assuada ou ajuntamento de dez pessoas estranhas para fazer mal a alguem, cousa que era permitida e usada pelos antigos Germanos e pelos Godos, segundo Tacito e CassioDORO.

Os desafios eram comuns antigamente e autorizados em certos casos, ordenando-os muita vez a própria Justiça, na crença medieval de que Deus fortalecia o braço do mais justo. Conhecido é o caso de Afonso VI de Castela, o qual querendo "abolir nos seus Estados o Officio Mossarabico, para the substituir o Romano, e não podendo conciliar o Clero, a 
Nobreza e o Povo, se escolherão para a decisão dous Cavalleiros, dos quais um sustentasse o Officio Romano, e o outro o Mossarabico". Em Paris, antes de Luiz VII, o próprio rei designava o lugar do desafio, e assistia ao embate acompanhado de toda a côrte. Só muito depois é que Papas, Bispos, Concilios e Reis proibiram as rixas, nascidas de falsas idéias de honra e hoje consideradas crimes em quasi toda parte.

O crime de ambito, ou compra de vótos, punido pelas Ordenações com longa pena de degredo, e condenado severamente pelas leis romanas, agóra, apesar de proibido pela letra da lei, é praticado até publicamente pelos govêrnos, numa aura de completa desmoralização.

A vadiagem tem sido geralmente qualificada de crime. E' do interêsse de cada individuo que todos se esforcem para o bem comum, cada qual procurando os meios lícitos da sua subsistencia, pois segundo a sabedoria popular da China: "se um vassalo não trabalha, há-de haver outro que padeça frio ou fome" Daí a punição dos parasitas, autorizada por Solon, e baseada, na Grecia, segundo Heropoto, em leis do velho Egito.

A punição dos vadios foi feita com prisão e açoites, na Inglaterra; com a forca, na Alemanha; com as galés, em Napoles; com o degredo, na França. As Ordenações, no capítulo dos "Crimes contra a Economia Pública" puniram com açoites e galés aqueles que vivessem "na ociosidade a custa de terceiros, sem buscarem meios de subsistirem; ou derem escandalo, e prejuizo ao público com a sua conduta" E com penas severas foram punidos os que protegeram ou ocultaram a vagabundagem alheia.

O Código Penal Brasileiro, inspirado no Código Penal Francês e lei de 27 de maio de 1885, no seu artigo 399 fundiu a vadiagem, a vagabundagem e a profissão ilícita. São elementos da contravenção, segundo o referido artigo, primeira parte: 
a) Falta de profissão, ofício ou qualquer mister em que ganhe a vida;

b) Falta de meio de subsistencia;

c) Falta de domicílio certo.

São elementos da contravenção da segunda parte do art. 399:

a) que o agente se entregue á ocupação proibida por lei ou manifestamente of ensiva da moral e dos bons costumes;

b) que faça disso meio de vida. O decreto legislativo n. 145 de 11 de Julho de 1893 , art. $2 .^{\circ}, \S 1 .^{\circ}$, assim restringiu os elementos da contravenção:

1) que o agente, homem ou mulher, maior de 14 anos, não esteja sujeito ao poder paterno, ou sob direção de tutores ou curadores;

2) que não tenha meios de subsistencia por fortuna própria ou profissão, arte, oficio, ocupação legal e honesta em que ganhe a vida;

3) que vagueie pela cidade na ociosidade.

Se bem que a lei diga de qualquer idade, a vadiagem só é punivel nos maiores de 14 anos, pois os menores desta idade e maiores de 9 anos, sem assistencia e vagabundos, formam a categoria dos menores abandonados, sujeitos apenas a providências administrativas. $O$ artigo $52, \S 10^{\circ}$ do Regulamento baixado com o decreto 6994 de 19 de Junho de 1908, diz que somente os maiores podem ser considerados vadios. Mas êsse regulamento, alem de ir contra disposições expressas de leis, é contraditorio e por isso inaceitavel.

E' o terceiro requisito, entretanto, que carateriza a vagabundagem: - o "vagar pela cidade na ociosidade" Esse caraterístico foi notado não só pelas leis e autores modernos, como tambem por jurisconsultos antigos: Julius Clarus, Farinacius e outros diziam: "Vagabundus proprie dicitur qui per mundum vagatur nec certum habet domicilium in quo habitet"

Nos processos de vadiagem, como nos de todas as contravenções, necessario se torna o requisito da voluntarieda- 
de do agente, pois escapam á repressão penal a vagabundagem involuntaria e a acidental. Os que não querem trabalhar, embora aptos e não tendo meios de subsistencia, os parasitas sociais que fazem da vagabundagem profissão, é que devem ser punidos enérgicamente, por eonstituirem, como os mendigos válidos, o estágio da criminalidade. Assim tambem entendeu o Projeto do Código Criminal Brasileiro, de Sá Pereira, elaborado pela sub-comissão e resultante da revisão do Projeto Oficial de 1928, juntando no seu artigo 470 a vagabundagem e a mendicância. E entretanto, no generoso e ativo Estado de S. Paulo, alguem com pretensões a estadista aplaudiu e recomendou oficialmente a vagabundagem e a mendicância!

As velhas leis puniam o luxo, confundindo-o talvez com a corrupção. Citava-se com freqüência, como exemplo de que o luxo e a corrupção andam juntos, o fato dos antigos Persas, sóbrios, virtuosos e pobres no tempo de Ciro, se terem corrompido depois da conquista da Asia, de onde trouxeram o gôsto pela riqueza. Mas, pergunta um cronista arguto, - "corromper-se-iam por terem conquistado a Asia, ou por terem tomado o seu luxo?" E conta: - "Atenas perdeu a sua fôrça, e as sua virtudes depois da guerra do Peloponeso, época da sua riquesa e do seu luxo. Porém não seria antes a causa real da decadencia de Atenas o abatimento que Pericles fez ao Areopago, e a passagem dos poderes executivo, e legislativo para as unãos do povo?"

Não nos parece que o luxo seja permanentemente um mal. Êle deverá ser, isto sim, mais ou menos permitido, segundo as condições financeiras das nações. Porisso, com certeza, é que os códigos de até agora abrogaram as leis que antigamente o proibiam, devido ao progresso das artes paralelo ao crescimento das riquesas. Hoje, contudo, diante da crise tremenda que assoberba o mundo e das conseqüentes questões sociais, a tendencia geral é a de diminuir e mesmo coibir o luxo, que dentro em pouco talvez seja considerado um crime, se não melhorarem as condições financeiras dos poros e das nações. 
Variada é ainda a lista dos fatos antigamente considerados delituósos e que as leis modernas não mencionam entre os crimes. As Ordenações no livro $5 .^{\circ}$, titulo 72 , puniam com a pena de degredo os nobres que matassem abelhas. As serenatas românticas junto ás casas das donzelas, as promessas de despacho na côrte, as brincadeiras com fogos de artifício, os bailes de negros forros, eram considerados atos criminosos, bem como eram delitos andar de noite depois do sino corrido, (o qual se tocava de Outubro ao fim de Março das oito ás nove horas, e de Abril a Setembro, das nove ás dez horas), ou não fechar lógo á noitinha as portas das escadas que davam serventia para a rua. Crimes eram a heresia, a apostasia, a blasfêmia, o perjúrio, a simonia, o sortilégio e a superstição, hoje sujeitos apenas ao nosso foro intimo.

Modernamente a maior parte das nações civilizadas segue o regime da monogamia, e pune a bigamía como um ato delituoso. É, esta, mais uma prova da relatividade dos crimes no tempo e no espaço. No tempo porquê quasi todos os póvos antigos toleravam a bigamia e o concubinato; no espaço, porquê ainda em nossos dias os orientais possuem muitas esposas e alimentam o luxo dos harens. Seguem o exemlo de Salomão que, segundo a História, teve setecentas mulheres e trezentas concubinas, e de Dario da Persia que teve de uma vez trezentas e sessenta e cinco companheiras.

O progresso e o refinamento da civilização hão-de fazer ainda aparecerem crimes que ninguem suspeitava que pudessem nascer. E' o que há-de notar quem estude as tendencias das novas idéias penais, que procuram dar aos juizes criminais a maior soma possivel de arbitrio e liberdade. Foi o que notou LEON DE LEON num recente artigo na "Giustizia Penale", criticando acerbamente o Código Penal Soviético, que dá aos Juizes o poder de decidirem, sem normas e sem limites, sôbre a natureza delituósa dos atos praticados, 
e que assim cria classes de crimes que hão-de variar segundo a variedade das conciências dos julgadores.

Pelos fatos que citámos é que se póde afirmar, sem medo de erro, que a natureza dos crimes há-de ser sempre relativa, porquê a sua estabilidade depende de uma impossivel identidade e invariabilidade de civilização, de cultura, de costumes e de sentimentos, em todas as épocas, entre todos os póvos e todas as nações do mundo. 